\title{
The use of sibutramine in the management of obesity and related disorders: An update
}

\author{
This article was published in the following Dove Press journal: \\ Vascular Health and Risk Management \\ II May 2009 \\ Number of times this article has been viewed
}

\section{Konstantinos Tziomalos \\ Gerasimos E Krassas \\ Themistoklis Tzotzas \\ Department of Endocrinology, Diabetes and Metabolism, Panagia General Hospital, Thessaloniki, Greece}

Correspondence: Themistoklis Tzotzas Al. Svolou 27, 54622, Thessaloniki, Greece Tel +302310287490

Fax +30231028 4827

Email tzotzas@otenet.gr
Aims: To review the major trials that evaluated the efficacy and safety of the use of sibutramine for weight loss and the impact of this agent on obesity-related disorders.

Methods and results: The most important articles on sibutramine up to January 2009 were located by a PubMed and Medline search. Sibutramine reduces food intake and body weight more than placebo and has positive effects on the lipid profile (mainly triglycerides and high density lipoprotein cholesterol), glycemic control and inflammatory markers in studies for up to one year. Preliminary studies showed that sibutramine may also improve other obesityassociated disorders such as polycystic ovary syndrome, left ventricular hypertrophy, binge eating disorder and adolescent obesity. The high discontinuation rates and some safety issues mainly due to the increase in blood pressure and pulse rate have to be considered. Additionally, it has not yet been established that treatment with sibutramine will reduce cardiovascular events and total mortality.

Conclusions: Sibutramine, in conjunction with lifestyle measures, is a useful drug for reducing body weight and improving associated cardiometabolic risk factors and obesity-related disorders. Studies of longer duration are required to determine the precise indications of the drug, to evaluate safety issues and to assess its efficacy on cardiovascular mortality.

Keywords: Sibutramine, obesity, weight loss, cardiometabolic risk factors, obesity-related disorders, side-effects

\section{Introduction}

The prevalence of obesity is increasing substantially in both developed and developing countries during the last decades. ${ }^{1}$ Almost two thirds of the adult US population is overweight and almost one third is obese. ${ }^{2}$ Similar high rates and trends were reported in certain European countries. ${ }^{3}$ Obesity, particularly when associated with abdominal fat distribution, increases the risk for cardiovascular morbidity and mortality. ${ }^{4,5}$ Overweight and obesity also increase the risk for cancer-related mortality and for all cause mortality ${ }^{6}$ and result in reduced life expectancy. ${ }^{7,8}$

Lifestyle measures are the cornerstone of prevention and treatment of obesity. ${ }^{9}$ However, adding antiobesity agents can be considered in obese patients who did not achieve sufficient weight loss after lifestyle modifications and if patients accept risks and benefits of these agents. ${ }^{9,10}$ Two agents are currently approved for longterm management of obesity, sibutramine and orlistat. The newer antiobesity drug rimonabant, a cannabinoid receptor antagonist, was recently suspended from the market due to increased incidents of suicidal behavior and depression among treated patients. ${ }^{11}$ submit your manuscript | www.dovepress.com

Dovepress 
Data regarding the efficacy and safety of sibutramine were reported in recent reviews. ${ }^{12,13}$ In the present paper we describe the mechanism of action of sibutramine and present the most important trials that evaluated the body weight-reduction potential of this agent. Furthermore, we comment on recent studies evaluating the effects of sibutramine on cardiometabolic risk factors and in specific pathological conditions related with obesity such as polycystic ovary syndrome, sleep apnea syndrome, left ventricular hypertrophy, binge eating disorder and in adolescent obesity. Finally, we evaluated studies comparing sibutramine with orlistat and address the safety issues associated with the use of this agent. The most important relevant articles on sibutramine until January 2009 were reviewed through a PubMed and Medline search.

\section{Mechanism of action}

Sibutramine induces weight loss by selectively inhibiting the neuronal reuptake of serotonin and norepinephrine within the hypothalamus. ${ }^{10}$ To a smaller degree it also inhibits the reuptake of dopamine. ${ }^{10}$ Studies in subjects who were not attempting to lose weight showed that sibutramine acts by reducing food intake. ${ }^{14,15}$ This appears to result from an increase in satiety and a reduction in appetite. ${ }^{15-19}$ It was also shown that sibutramine might augment energy expenditure in both the basal and fed states. ${ }^{16}$ In addition, sibutramine prevented the decrease in energy expenditure and basal metabolic rate that follows weight loss. ${ }^{18,20,21}$ However, other studies did not find any change in metabolic rate with sibutramine. ${ }^{22}$ The action on thermogenesis seems of minor importance in weight reduction.

Besides increased sympathetic activity, sibutramine treatment in animals and in humans may alter central neuropeptide Y (NPY), and proopiomelanocortin (POMC) mRNA levels and, additionally, the potent anorexigenic hormones leptin and insulin..$^{23,24}$ Concerning the effects on leptin, it was reported that sibutramine might maintain or even increase leptin transport into the brain during weight loss, while this did not occur during orlistat treatment. ${ }^{25}$

\section{Studies assessing the weight-lowering potential of sibutramine}

In an early dose-ranging study in 235 overweight or obese patients, $10 \mathrm{mg}$ sibutramine per day were as effective as $15 \mathrm{mg} /$ day; both doses were more effective than the $5 \mathrm{mg}$ /day dose. ${ }^{26}$ In another study in 485 obese men, sibutramine (10 or $15 \mathrm{mg} /$ day for one year) and behavior treatment reduced body weight, body mass index (BMI), waist circumference, and waist/hip ratio (WHR) more than behavior therapy and placebo. ${ }^{27}$ Greater proportions of patients in both sibutramine groups lost at least $5 \%$ or $10 \%$ of their baseline body weight compared with the placebo group. ${ }^{27}$ Both doses were more effective than placebo and the $15 \mathrm{mg} /$ day dose was more effective than the $10 \mathrm{mg} /$ day dose. ${ }^{27} \mathrm{In}$ a larger doseranging study in 1047 obese patients, sibutramine $(1,5,10$, 15,20 , or $30 \mathrm{mg} /$ day for 24 weeks) induced dose-dependent weight loss, which was significantly higher than placebo. ${ }^{28}$ In a meta-analysis, weight loss with sibutramine was larger with the $15 \mathrm{mg} /$ day dose. ${ }^{29}$ The dosage range of sibutramine is 5 to $15 \mathrm{mg} /$ day; $10 \mathrm{mg} /$ day as a single daily dose is the recommended starting dose. ${ }^{30}$

In another study in 322 overweight or obese patients, sibutramine ( $20 \mathrm{mg}$ /day for 24 weeks) reduced body weight, BMI and waist circumference and improved the quality of life more than placebo. ${ }^{31}$ In a recent study in 362 obese patients, sibutramine ( $15 \mathrm{mg} /$ day for 54 weeks) reduced body weight by a mean of $3.0 \mathrm{~kg}$ more than placebo. ${ }^{32}$ The efficacy of sibutramine appears to be similar in every day clinical practice. In a nonblinded study in 588 obese patients, sibutramine $(10-15 \mathrm{mg} /$ day for one year) within a weight management program induced greater reductions in body weight, BMI, waist circumference and body fat than the weight management program alone. ${ }^{33}$ More patients in the sibutramine group experienced $>5 \%$ weight loss $(47.3 \%$ vs $19.1 \%$ in the weight management program only group; $\mathrm{p}<0.001)^{33}$

In a recent meta-analysis of randomized placebocontrolled trials of sibutramine of at least one year in duration (10 studies with 2,623 patients), sibutramine reduced body weight by $4.2 \mathrm{~kg}$ ( 3.6 to $4.7 \mathrm{~kg}$ ) more than placebo. ${ }^{34}$ A higher proportion of patients treated with sibutramine achieved $>5 \%$ weight loss $(55 \%$ vs $27 \%$ in the placebo group) or $>10 \%$ weight loss ( $28 \%$ vs $10 \%$ in the placebo group). ${ }^{34}$ There was also a greater reduction in BMI in the sibutramine group. Sibutramine appears to reduce visceral more than subcutaneous adiposity. In the meta-analysis by Rucker and colleagues ${ }^{34}$ there was a $4 \mathrm{~cm}$ decrease in waist circumference with sibutramine. In a subgroup of patients in the Sibutramine Trial of Obesity Reduction and Maintenance (STORM) study, computed tomography showed a preferential reduction in visceral fat. ${ }^{35}$ Similar results were reported in a smaller study using magnetic resonance imaging to assess changes in adipose tissue. ${ }^{36}$

Sibutramine also prevents weight regain when administered after a dietary intervention. In the STORM study 605 obese patients were given sibutramine $(10 \mathrm{mg} /$ day $)$ and followed a low-energy diet for six months. ${ }^{37}$ Patients achieving $>5 \%$ 
weight loss after six months $(n=467)$ were randomly allocated to continue sibutramine $(10 \mathrm{mg}$ /day uptitrated to $20 \mathrm{mg}$ /day if weight regain occurred; $\mathrm{n}=350$ ) or placebo ( $n=114$ ) for 18 months. ${ }^{37}$ The sibutramine group had less weight regain than the placebo group. ${ }^{37}$ More patients in the sibutramine group maintained $\geq 80 \%$ of the weight loss achieved during the first 6 months of the study (43\% vs 16\% in the placebo group; $\mathrm{p}<0.001) .{ }^{37}$ Some studies showed that sibutramine can prevent weight regain after short-term (1-3 months) very-low-calorie diet. ${ }^{38,39}$ In these patients, treatment with sibutramine for 12-18 months maintained weight loss in a higher proportion of patients than placebo. ${ }^{38,39}$ In some of these studies, sibutramine induced additional weight loss and a reduction in waist circumference. ${ }^{38}$ A very recent review on clinical trials of weight loss maintenance revealed that treatment with sibutramine combined with lifestyle measures was efficacious in reducing weight regain after weight loss. ${ }^{40}$

It should be mentioned that when sibutramine is combined with behavior therapy the resulting weight loss appears to be more pronounced. In a study in 53 obese women, combining sibutramine (10 to $15 \mathrm{mg} /$ day for one year) with behavior therapy or portion-controlled diet induced greater reductions in body weight than sibutramine alone. ${ }^{41}$ In a larger study in 224 obese patients, sibutramine (10 to $15 \mathrm{mg}$ /day for one year) with behavior therapy resulted in greater weight loss than either sibutramine or behavior therapy alone. ${ }^{42}$ The prevalence of metabolic syndrome (MetS) was also reduced more in the former group and this was attributed to the greater weight loss in this group. ${ }^{43}$

Interestingly, some studies showed that intermittent treatment with sibutramine might be as effective as continuous administration of this agent. ${ }^{44}$ In 1,001 obese patients, continuous treatment with sibutramine (15 mg/day) for 48 weeks induced similar weight and waist circumference reductions with intermittent treatment (sibutramine $15 \mathrm{mg}$ /day only during weeks $1-12,19-30$ and $37-48) .{ }^{44}$ In addition, the proportion of patients experiencing a serious adverse event was lower in the intermittently treated group. ${ }^{44}$

It is of interest that weight loss achieved during the first month of sibutramine treatment was predictive of long-term weight loss. ${ }^{28,41}$ A meta-analysis of seven sibutramine studies $(\mathrm{n}=928)$ showed that a weight loss of $4 \mathrm{~kg}$ at three months was the most sensitive predictor of achieving $>5 \%$ weight loss at 12 months. ${ }^{45}$ It was suggested that it might be reasonable to discontinue sibutramine in patients who do not lose at least $5 \%$ of their body weight within the first 3-6 months. ${ }^{46}$ However, a Swedish study suggested that sibutramine is not discontinued in the majority of patients who do not achieve this target. ${ }^{47}$

Other predictors of weight loss during sibutramine treatment were also identified in some reports. In the STORM study, higher body weight at baseline was the only predictor of greater weight loss at six months and weight maintenance at 24 months. ${ }^{48}$ In other studies, higher baseline BMI also predicted greater weight loss at 4 and 12 months. ${ }^{19}$ A younger age, lower depression scores, less restrained eating and lower energy intake at baseline also appear to predict greater weight loss. ${ }^{19,49,50}$ Preliminary findings suggest that specific genes might modulate the response to sibutramine treatment. ${ }^{51-53}$ In 149 obese women, the GG and AA genotypes of the phenylethanolamine $\mathrm{N}$-methyltransferase gene (the ratelimiting enzyme in catecholamine biosynthesis) were associated with greater weight loss with sibutramine than the AG genotype. ${ }^{51}$ Another study in 111 patients reported that the GN 33 CC genotype predicted $>5 \%$ weight loss with sibutramine..$^{52}$ Patients with the GN $\beta 3$ TC/TT genotypes derived no benefit from sibutramine. ${ }^{52}$ The GN $\beta 3$ gene encodes the $\beta 3$ subunit of the G-proteins, which are the second messengers of the adrenergic and serotoninergic receptors. ${ }^{52,53}$ In contrast, in a more recent study in 181 subjects, the GN 33 TC/TT genotypes were associated with greater weight loss with sibutramine treatment. ${ }^{53}$ The $\alpha 2 \mathrm{~A} \mathrm{CC}$ and $5 H T T L P R$ LS/SS genotypes and the combinations of these 3 genotypes (GN 33 $\mathrm{TC} / \mathrm{TT}, \alpha 2 \mathrm{~A}$ CC and $5 H T T L P R$ LS/SS) were also associated with greater weight loss. ${ }^{53}$ The $\alpha 2 \mathrm{~A}$ and $5 H T T L P R$ genes encode the $\alpha 2 \mathrm{~A}$ adrenoreceptor and the serotonin transporter protein, respectively. ${ }^{53}$

\section{Sibutramine and cardiometabolic risk factors}

Overweight and obesity increase the risk for developing type 2 diabetes mellitus (T2DM). ${ }^{5,54}$ On the other hand, in patients with impaired glucose tolerance (IGT) or impaired fasting glucose (IFG), weight loss resulting from lifestyle measures reduced the risk for developing T2DM. ${ }^{55,56}$ More importantly, intentional weight loss in overweight diabetic patients reduced cardiovascular and all cause mortality. ${ }^{57,58}$ In several studies in obese or overweight diabetic patients, sibutramine (5-20 mg/day for 12 weeks to six months) reduced body weight, BMI, waist circumference and body fat more than placebo. ${ }^{59-62}$ Quality of life also improved in the sibutramine group, particularly in patients who lost $>5 \%$ body weight. ${ }^{61}$ In a longer-term study, 59 overweight or obese diabetic were treated with meal replacement products and intermittent low-calorie diet and were randomized to receive 
sibutramine for two years or only sibutramine during the second year of the study. ${ }^{63}$ Body weight reduction was similar in the two groups and there was no further weight loss during the second year of sibutramine treatment. ${ }^{63}$ Meta-analyses suggested that weight loss with sibutramine is similar in diabetic and nondiabetic obese patients. ${ }^{34,64}$ In the study by Rucker and colleagues ${ }^{34}$ placebo subtracted weight losses in patients with T2DM averaged 5\% and the respective rate in nondiabetic patients was $4.3 \%$. Another meta-analysis in patients with T2DM showed that sibutramine resulted in a weight reduction averaging $-3.3 \%$ and a modest decrease of glycosylated hemoglobin $\left(\mathrm{HbA}_{1 \mathrm{c}}\right)$ by $-0.7 \%{ }^{65}$

Sibutramine-induced weight loss is accompanied with improvements in lipid profile and, in earlier studies, mainly a substantial increase in high-density lipoprotein cholesterol (HDL-C) levels was observed. ${ }^{28,31,32,37}$ In the STORM study, ${ }^{37}$ sibutramine treatment for 24 months increased HDL-C levels more in men than in women $(11.2 \%$ vs $8.5 \%$ more than placebo, respectively) and similar improvements were reported in a 12 month study by Abfelbaum et $\mathrm{al}^{38}$ The rise in HDL-C levels was suggested to be greater than that expected to result from weight loss. ${ }^{37}$ In two recent meta-analyses however, it was evident that the effect of the drug on HDL-C was not so important. HDL-C levels increased by $2.53 \%{ }^{66}$ and $0.04 \mathrm{mmol} / \mathrm{l}^{34}$ more than placebo and these changes were probably attributable to the weight loss. A decrease in triglycerides (TG) levels was reported in some sibutramine studies $^{28,32,37}$ but not in others. ${ }^{31,33,42}$ The reduction in TG levels also correlated with the weight loss. ${ }^{37} \mathrm{~A}$ fall in low-density lipoprotein cholesterol (LDL-C) levels was also described ${ }^{28}$ but this was not confirmed by most reports. ${ }^{31-33,37,42}$ In a recent meta-analysis sibutramine reduced TG levels more than placebo by $0.2 \mathrm{mmol} / 1 .{ }^{34}$ Changes in LDL-C and $\mathrm{HbA}_{1 \mathrm{c}}$ levels did not differ between groups. ${ }^{34}$ Similar changes in lipid profile are observed in diabetic patients treated with sibutramine but there is also an improvement in glycemic control in this population. ${ }^{67}$

Elevated serum uric acid levels is frequently present in obese patients and might be associated with increased vascular risk. ${ }^{68}$ In some studies, sibutramine lowered serum uric acid levels ${ }^{27,28,38}$ and this reduction was proportional to weight loss. ${ }^{27}$

Insulin resistance (IR) coexists very often with central obesity and weight loss may ameliorate this condition and associated metabolic disorders. ${ }^{69}$ In a weight loss nonrandomized study, ${ }^{70}$ sibutramine ameliorated IR parameters including serum insulin, homeostasis model assessment (HOMA) index, serum free fatty acids and TG, before any significant change of body weight and fat distribution suggesting that, sibutramine might improve insulin sensitivity directly. Other studies, however, did not confirm this finding but demonstrated that the improvement in IR by the drug was dependent on weight reduction per se. ${ }^{71,72}$ Until now, a direct action of sibutramine on IR is not proven.

Nonalcoholic fatty liver disease is frequently present in overweight and obese patients and may progress to nonalcoholic steatohepatitis (NASH) or cirrhosis. ${ }^{73}$ The fundamental derangement in nonalcoholic fatty liver disease is IR. In patients with NASH, sibutramine reduced transaminase and $\gamma$-glutamyltransferase levels and induced a regression in ultrasonography-assessed steatosis. ${ }^{74}$

Inflammation plays an important role in the pathogenesis of atherosclerosis. ${ }^{75}$ Overweight and obese patients frequently have elevated levels of inflammatory markers. ${ }^{76-79}$ Sibutramine reduced high sensitivity C-reactive protein (hsCRP) levels in some studies ${ }^{80,81}$ but not in others. ${ }^{82}$ Sibutramine along with diet and exercise reduced the serum levels of the pro-inflammatory cytokines tumor necrosis factor $\alpha$ (TNF $\alpha$ ) and interleukin 6 (IL-6) and increased the serum levels of the anti-inflammatory cytokine IL-10. ${ }^{83}$ These anti-inflammatory effects were independent of weight loss in some studies ${ }^{80}$ but were related to weight loss in others. ${ }^{81,83}$

Leptin, adiponectin, and resistin are important adipokines and play a role in energy homeostasis, glucose metabolism, and weight regulation. ${ }^{84}$ In some studies, sibutramine reduced serum resistin and leptin levels and increased serum adiponectin levels ${ }^{25,81,83,85}$ and these effects were associated with improvements in IR and metabolic risk factors. ${ }^{81,83}$ The observed changes in adipokine levels also correlated with weight loss. ${ }^{25,81,83}$ However, sibutramine did not affect leptin or adiponectin levels in other reports. ${ }^{82,86,87}$

Endothelial dysfunction might represent an early stage of the atherosclerotic process. ${ }^{75}$ Endothelial dysfunction is frequently present in obese patients and correlates with the degree of abdominal obesity. ${ }^{88,89}$ In 80 obese patients with coronary heart disease (CHD), sibutramine $(10 \mathrm{mg} /$ day for four months) improved endothelial function. ${ }^{80}$ The improvement in endothelial function correlated with the decrease in hsCRP levels but not with the change in body weight. ${ }^{80}$

Left ventricular hypertrophy (LVH) is associated with increased vascular and all cause mortality in hypertensive patients ${ }^{90}$ and in the general population..$^{90,91}$ In hypertensive patients, regression of LVH with antihypertensive treatment reduces vascular risk. ${ }^{92}$ LVH appears to be more prevalent in obese patients than in subjects with normal weight regardless of the presence of hypertension. ${ }^{93,94}$ In obese patients, 
sibutramine (10-20 mg/day for 3-6 months) reduced left ventricular mass whereas no significant change was observed in the placebo group..$^{95,96}$ This reduction correlated with the decrease in body weight. ${ }^{95}$

\section{Therapeutic use of sibutramine in obesity-related disorders}

Obstructive sleep apnea is a disorder frequently observed in obese patients and is associated with increased risk for developing hypertension. ${ }^{97,98}$ In an uncontrolled study in 87 obese patients, sibutramine (10 mg/day for six months) reduced body weight and improved markers of obstructive sleep apnea severity (respiratory disturbance index and Epworth score). ${ }^{99}$ There was a significant correlation between weight loss and the improvement in obstructive sleep apnea markers. ${ }^{99}$ In a smaller, shorter-term, placebocontrolled study (20 patients with obstructive sleep apnea given sibutramine $15 \mathrm{mg}$ /day for one month) sibutramine had no effect on polysomnographic variables (sleep efficiency and apnea-hypopnea index). ${ }^{100}$ However, no change in body weight was observed in this study. ${ }^{100}$

Polycystic ovary syndrome (PCOS) is a complex, frequent condition affecting 5\%-10\% of premenopausal women, characterized by hyperandrogenemia, hirsutism and oligomenorrhea or amenorrhea. A substantial proportion of these patients are overweight or obese and insulin resistant, and are at high risk for subsequent cardiovascular disease. ${ }^{101}$ In two small studies in overweight or obese women with PCOS (total $\mathrm{n}=101)$, sibutramine $(10-15 \mathrm{mg} /$ day for six months) reduced body weight and BMI more than lifestyle modification alone. ${ }^{102,103}$ Triglyceride levels and markers of androgen excess decreased more in the sibutramine group but menstrual frequency did not differ significantly between groups. ${ }^{102,103}$ In one of these studies insulin sensitivity was also increased. ${ }^{102}$ In another study in 40 obese women with PCOS, sibutramine (10 mg/day) reduced body weight, BMI and markers of androgen excess to a similar extent as oral ethinyl estradiol plus cyproterone acetate $(35 \mu \mathrm{g} / 2 \mathrm{mg}) .{ }^{104}$ However, only sibutramine reduced WHR and improved insulin sensitivity. ${ }^{104}$ On the other hand, HDL-C levels increased in the ethinyl estradiol plus cyproterone acetate group but remained stable in the sibutramine group. ${ }^{104}$ Combining sibutramine and ethinyl estradiol plus cyproterone acetate did not provide further benefits over sibutramine monotherapy except for an increase in HDL-C levels. ${ }^{104}$ Despite these promising findings, it should be noted that sibutramine is contraindicated during pregnancy and should be discontinued in these patients in case of pregnancy. Overall, preliminary data suggest that sibutramine in women with PCOS could represent a therapeutic option, provided that its use is monitored carefully.

The use of several antipsychotic agents is associated with significant weight gain. ${ }^{105}$ In a study in 37 obese or overweight patients with schizophrenia or schizoaffective disorder treated with olanzapine, sibutramine (5-15 mg/day for 12 weeks) reduced body weight, $\mathrm{BMI}$, and waist circumference more than placebo. ${ }^{106}$ However, three months after the end of the study, changes from baseline in all these parameters were similar in the two groups. ${ }^{106}$ In two other reports, sibutramine (5-20 mg/day for 12 weeks) did not reduce body weight more than placebo in patients with chronic schizophrenia treated with olanzapine $(n=28)$ when combined with metformin $(850-1700 \mathrm{mg} / \text { day })^{107}$ or in obese patients with schizophrenia or schizoaffective disorder treated with clozapine $(n=21)$ when given alone. ${ }^{108}$

Binge eating disorder is characterized by recurrent binge eating in the absence of inappropriate compensatory behaviors and/or extreme dietary restraint and is distinguishable from both bulimia nervosa and obesity. ${ }^{109}$ Binge eating disorder very often results in overweight and obesity. Sibutramine appears to be useful in the management of these patients. An early, uncontrolled study in 10 patients reported a reduction in body weight and in the number of binge eating episodes when sibutramine (15 mg/day) was given for 12 weeks. ${ }^{110}$ In placebo-controlled studies (total $\mathrm{n}=$ 384 ), sibutramine (10-15 mg/day for 12-24 weeks) reduced body weight and the frequency of binge eating episodes more than placebo. ${ }^{111-113}$ In one report, depression scores were also reduced more in the sibutramine group. ${ }^{111}$

Finally, sibutramine was administered in a small group of obese adults with hypopituitary disease for 11 months. ${ }^{114}$ It was previously shown that substituted patients with hypopituitarism have lower sympathoadrenal activity but a normal energy expenditure when compared with controls. ${ }^{115}$ Therefore, the rationale for using sibutramine in such patients was that, besides reducing food intake, it could enhance sympathoadrenal activity and, thus, induce an adequate weight loss. ${ }^{114}$ The results of the study showed that obese patients with hypopituitary disease exhibited the same favorable changes in anthropometric indices, body composition and metabolic parameters as controls with simple obesity.

\section{The case of childhood obesity}

The prevalence of childhood obesity has increased dramatically during the last decades ${ }^{116}$ and, in the US, current prevalence of overweight in children and adolescents reaches 
approximately $31.9 \%$ and that of obesity $16.3 \% .{ }^{117}$ Similar rates were reported in other countries. ${ }^{16,118}$ In cross-sectional studies in children and adolescents, overweight is associated with increased prevalence of IFG, T2DM, hypertension, and dyslipidemia. ${ }^{120,121}$ A significant proportion of overweight children and adolescents will become obese adults. ${ }^{122,123}$ More importantly, overweight and obese children and adolescents have increased risk for CHD and all cause mortality. ${ }^{124,125}$ Sibutramine might be useful in obese adolescents. ${ }^{17,126-131}$ In an early placebo-controlled trial in 82 obese adolescents receiving behavior therapy and sibutramine (starting dose $5 \mathrm{mg} /$ day and uptitrated to $15 \mathrm{mg} /$ day) the authors demonstrated a weight reduction significantly higher in the sibutramine group than in the placebo group (by $4.6 \mathrm{~kg}$ ) after six months. ${ }^{17}$ All participants received sibutramine for the following six months. ${ }^{17}$ Those who continued to receive sibutramine gained a mean of $0.8 \mathrm{~kg}$ whereas those who were switched from placebo to sibutramine lost a mean of $1.3 \mathrm{~kg}$ ( $\mathrm{p}=0.057$ between groups). ${ }^{17}$ Interestingly, there was no difference in weight loss at 12 months between patients given sibutramine for 12 months and those given sibutramine for six months. ${ }^{17}$ In another study in 60 obese adolescents, sibutramine (10 mg/day given for six months) reduced body weight and BMI by a mean of $7.9 \mathrm{~kg}$ and $2.7 \mathrm{~kg} / \mathrm{m}^{2}$ respectively more than placebo $(\mathrm{p}<0.001) .{ }^{127}$ Changes in lipid profile and IR did not differ between groups in any of these two studies. ${ }^{17,127}$ In a more recent and larger study in 498 obese adolescents receiving behavior therapy, sibutramine $(10 \mathrm{mg}$ /day uptitrated to $15 \mathrm{mg}$ /day at six months if BMI was not reduced by $>10 \%$ ) reduced body weight by a mean of $8.4 \mathrm{~kg}$ and BMI by a mean of $2.9 \mathrm{~kg} / \mathrm{m}^{2}$ more than placebo after 12 months. ${ }^{126}$ There was also a greater reduction in TG levels and in IR and a larger increase in HDL-C levels in the sibutramine group. ${ }^{126} \mathrm{~A}$ recent meta-analysis reported a $2.4 \mathrm{~kg} / \mathrm{m}^{2}$ (with a $95 \%$ confidence interval [CI] of 1.8-3.1) in BMI loss when sibutramine was given to obese adolescents. ${ }^{128}$ In this meta-analysis, adolescents taking the drug had higher rates of elevated blood pressure (BP) and pulse rate than adolescents taking placebo. ${ }^{128}$

The usefulness of sibutramine was tested in children with hypothalamic obesity. These patients have multiple pituitary hormone deficiencies due to hypothalamic genetic disorders or hypothalamic damage from tumor, surgery and/ or irradiation, resulting in intractable weight gain resistant to conventional therapeutic measures. ${ }^{129}$ Although different therapeutic strategies have been attempted in hypothalamic obesity, successful treatment has been rarely achieved. ${ }^{129,130}$ In a placebo-controlled study in 50 children and adolescents,
7-20 years of age, with hypothalamic obesity or obesity with aggravating syndromes (mental retardation, autism or attention deficiency hyperactivity disorder), sibutramine (10-15 mg/day for 20 weeks) reduced BMI SD score value significantly as well as body fat and was well tolerated. ${ }^{131}$ However, discontinuation of sibutramine was followed by regain of $60 \%$ of the weight loss. ${ }^{131}$

It should be noted that sibutramine is currently indicated only in patients $\geq 16$ years of age. Moreover, current guidelines recommend lifestyle measures as first-line treatment in obese children and adolescents. ${ }^{132}$ If these modifications are ineffective, medication can be considered in specialized centers in children $>11$ years of age with BMI of $>95$ th percentile and significant comorbidities or with BMI of $>99$ th percentile. ${ }^{132}$

\section{Comparative studies with other antiobesity agents}

Sibutramine and orlistat are the only approved agents for the long-term management of obesity and a number of studies compared these agents. Sibutramine (10-20 mg/day for 12 weeks to 12 months) reduced body weight and BMI more than orlistat $(360 \mathrm{mg} /$ day $)$ in three studies in obese patients (total $\mathrm{n}=325) .{ }^{133-135}$ However, in two other studies (total $\mathrm{n}=259$ ), sibutramine (10 mg/day given for 12-24 weeks) and orlistat $(360 \mathrm{mg} /$ day) induced similar reductions in body weight, BMI, and waist circumference. ${ }^{136,137}$ In another study in 115 hypertensive obese patients, sibutramine $(10 \mathrm{mg} /$ day given for 12 months) and orlistat (360 mg/day) reduced body weight, BMI, waist circumference and WHR to a similar extent. ${ }^{138}$ A recent meta-analysis of seven studies comparing head-to head sibutramine with orlistat $(n=851)$ reported a $2.2 \mathrm{~kg}$ greater weight loss with sibutramine. ${ }^{139}$ Changes in lipid profile appear to be similar with these two agents. ${ }^{135,136,138}$ However, there was a greater improvement in depression score in patients assigned to sibutramine. ${ }^{137}$ In most studies, BP fell in the orlistat group and did not change or increased in the sibutramine group. ${ }^{135,136,138,140}$ However, total adverse events were fewer in the sibutramine-allocated group. ${ }^{138,140}$

Combining sibutramine and orlistat (10 mg and $360 \mathrm{mg} /$ day, respectively, for 3-6 months) did not provide additional benefits over sibutramine monotherapy in obese patients. ${ }^{133,134}$ Interestingly, a small study in 34 women who had received sibutramine for one year showed that adding orlistat to sibutramine for 16 weeks did not induce further weight loss. ${ }^{141}$ In another study in 198 obese patients, combining sibutramine with an experimental selective antagonist of the receptor 5 of the orexigenic neuropeptide $\mathrm{Y}$ did not result 
in additional weight loss compared with sibutramine alone after 24 weeks. ${ }^{136}$

\section{Safety considerations}

Obesity increases the risk for developing hypertension. ${ }^{5,142,143}$ In addition, hypertension is more prevalent in overweight and obese individuals. Weight loss resulting from lifestyle modifications lowers BP and also reduces the risk for developing hypertension. ${ }^{144,145}$ In contrast, sibutramine increased BP levels compared with placebo in several trials despite the reduction in body weight. ${ }^{37,62}$ Other studies reported an increase only in diastolic BP (DBP) and not in systolic BP (SBP) ${ }^{27,146}$ and some no change in BP levels. ${ }^{42,44,59-61}$ A meta-analysis reported a significant increase in SBP and DBP levels (by 1.6 and $2.4 \mathrm{mmHg}$, respectively) in patients treated with sibutramine. ${ }^{34}$ Another meta-analysis reported that the increase in both SBP and DBP appears to be greater when the initial body weight is $>92 \mathrm{~kg} .{ }^{29}$

Sibutramine increases BP levels due to a peripheral sympathomimetic effect. ${ }^{146-149}$ Sibutramine stimulated the expression of $\alpha 2$ and $\beta 1$ adrenoreceptor genes in adipose tissue and increased plasma epinephrine and norepinephrine levels. ${ }^{142}$ Interestingly, sibutramine also exerts a central sympatholytic action, which might blunt its peripheral sympathomimetic effects. ${ }^{146-149}$

Sibutramine (10-20 mg/day for 12-52 weeks) was administered to hypertensive patients in several clinical studies and reduced body weight, BMI, waist circumference and WHR more than placebo. ${ }^{87,138,150-153}$ In addition, sibutramine reduced TG and uric acid levels and increased HDL-C levels. ${ }^{150,151,153}$ Quality of life also improved in the sibutramine group. ${ }^{150}$ In a recent meta-analysis of sibutramine studies in hypertensive patients, sibutramine reduced body weight by $3.7 \mathrm{~kg}$ more than placebo. ${ }^{154}$ Subgroup analyses in other meta-analyses suggested that weight loss with sibutramine is similar in hypertensive and normotensive obese patients. ${ }^{34,64}$ Even though sibutramine increased BP when given to hypertensive patients, ${ }^{150-152}$ it did not compromise BP control when hypertension was well controlled with angiotensin-converting enzyme inhibitors, ${ }^{151}$ calcium channel blockers, ${ }^{150}$ or beta blockers. ${ }^{152}$ It was also reported that the sibutramine-induced increase in BP is not greater in hypertensive patients. ${ }^{146}$ However, it should be emphasized that regular monitoring of $\mathrm{BP}$ and pulse rate is recommended in patients given sibutramine. In addition, sibutramine should be given with caution in patients with controlled hypertension and is contraindicated in patients with uncontrolled hypertension.
Increased heart rate is another side effect of sibutramine and was observed in most studies. ${ }^{27,32,33,37,59,61} \mathrm{~A}$ meta-analysis reported an increase in pulse rate by 4.5 beats $/ \mathrm{min}$ in sibutramine-treated patients. ${ }^{34}$ In the general population, elevated heart rate is associated with increased vascular risk. ${ }^{155,156}$ but it is not clear whether the sibutramine-induced increase in heart rate is also harmful.

Recently, treatment with sibutramine was associated in rare cases with QT interval prolongation which could lead to ventricular fibrillation and cardiac arrest. ${ }^{157,158}$ Therefore, monitoring of the electrocardiogram might be indicated in patients treated with sibutramine. ${ }^{157}$ In addition, concomitant use of sibutramine with other drugs likely to prolong QT (eg, certain antipsychotics, antidepressants, and antiarrhythmic agents) should probably be avoided. ${ }^{157}$

Dry mouth, constipation, nausea, and insomnia are other side effects of sibutramine. ${ }^{27,30,31,34}$

Overall, sibutramine is contraindicated in patients with established coronary heart disease, previous stroke, heart failure, or cardiac arrhythmias. ${ }^{30}$ In addition, it should not be administered to patients receiving monoamine oxidase inhibitors, selective serotonin reuptake inhibitors, sumatriptan, dihydroergotamine, meperidine, methadone, pentazocine, fentanyl, lithium or tryptophan. ${ }^{13,30}$ However, a Swedish study reported that $28 \%$ of the patients prescribed sibutramine had one or more contraindications to its use. ${ }^{47}$

In the larger sibutramine studies, discontinuation rates at one and two years of treatment were $19 \%-49 \%$ and $42 \%$, respectively. ${ }^{27,37,44}$ Drop-out rates at one and two years were similarly high in the placebo groups in the latter studies (27\%-51\% and 50\%, respectively). ${ }^{27,37,44}$ Interestingly, a population-based study suggested that these rates might be even higher in clinical practice. ${ }^{159}$ Persistence rates at six months, one and two years were $26 \%, 8 \%$, and $2 \%$, respectively. ${ }^{159}$ In the same study, approximately $60 \%$ of the patients did not fill in a second prescription of sibutramine. ${ }^{159}$ In other population studies, $41.8 \%-59.1 \%$ of the patients had stopped sibutramine within three months of starting treatment. ${ }^{160,161}$ Besides side effects, perceived low efficacy and cost might explain these high discontinuation rates. ${ }^{159-161}$

The ongoing Sibutramine Cardiovascular Outcome Trial (SCOUT) will assess the effect of sibutramine (10-15 mg/day) on vascular events in $>9,000$ obese and overweight patients with either established vascular disease or T2DM and another vascular risk factor. ${ }^{162}$ Preliminary safety results showed that sibutramine was safe and well tolerated in this high-risk population. ${ }^{163}$ 
The effects of sibutramine on weight loss and on associated risk factors and diseases are summarized in the Table 1.

\section{Conclusions}

Sibutramine, a selective inhibitor of central neuronal reuptake of serotonine and noradrenaline, reduces food intake and body weight more than placebo and has beneficial effects on the lipid profile, glycemic control and inflammatory markers in studies for up to one year. The drug may be beneficial in obese patients with metabolic disturbances in cases where

Table I Effects of sibutramine on obesity and related disorders

\begin{tabular}{ll}
\hline Anthropometric parameters & Effect \\
\hline Body weight & $\downarrow$ \\
Body mass index & $\downarrow$ \\
Waist circumference & $\downarrow$ \\
Waist/hip ratio & $\downarrow$ \\
Body fat & $\downarrow$ (Particularly abdominal fat)
\end{tabular}

\section{Cardiometabolic parameters}

Metabolic risk factors
HDL cholesterol

Triglycerides

LDL cholesterol

$\mathrm{HbA}_{\mathrm{Ic}}$ levels

Serum uric acid levels

\section{Inflammatory markers}

High-sensitivity C-reactive protein

Pro-inflammatory cytokines

(TNF- $\alpha$, IL-6)

Anti-inflammatory cytokines (IL-I0)

\section{Serum adipokine levels}

Leptin

Adiponectin

Resistin

Endothelial function

Left ventricular hypertrophy

Nonalcoholic steatohepatitis

Blood pressure

Pulse rate

$\uparrow$

$\downarrow$

$\rightarrow$

$\downarrow$ (In diabetic patients)

$\downarrow$

$\downarrow$

$\downarrow$

$\uparrow$

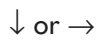

$\uparrow$ or $\rightarrow$

$\downarrow$

(+)

$\downarrow$

$(+)$

$\uparrow$

$\uparrow$

\section{Obesity-related disorders}

Sleep apnea syndrome

Possible (+)

Polycystic ovary syndrome

Binge eating disorder

(+)

(+)

Hypothalamic obesity
Abbreviations: HDL, high-density lipoprotein; LDL, low-density lipoprotein;TNF- $\alpha$, tumor necrosis factor- $\alpha ; \mathrm{HbA}_{1 \mathrm{c}}$, glycosylated hemoglobin $\mathrm{A}_{j} ; \mathrm{IL}-6$, interleukin-6; IL-I0, interleukin- $10 ; \rightarrow$, no effect; $\downarrow$, decrease; $\uparrow$, increase; (+), improvement. a lack of satiety or frequent snacking is an obstacle and limits weight reduction. Preliminary studies showed that sibutramine could be used in specific pathological situations such as polycystic ovary syndrome, sleep apnea syndrome, hypothalamic obesity and in obese adolescents. However, the increase in BP and pulse rate raises safety concerns. The high discontinuation rate should also be noticed. Another major limitation of sibutramine is that significant weight regain is frequently observed after treatment discontinuation. This implies that treatment with this agent should be long term, if not lifelong, if we aspire to sustained reductions in weight. However, most of the weight loss during sibutramine treatment occurs during the first six months of treatment and little additional weight loss is observed afterwards. Moreover, there are no sibutramine studies longer than two years and accordingly sibutramine is approved for use only for a limited period of time. Finally, it is unclear whether treatment with sibutramine will reduce cardiovascular events.

Until more conclusive evidence on the efficacy and safety of sibutramine are available, lifestyle measures should remain the mainstay of the management of obesity.

\section{Disclosure}

The authors report no conflicts of interest in this work.

\section{References}

1. James WP. The epidemiology of obesity: the size of the problem. J Intern Med. 2008;263(4):336-352.

2. Ogden CL, Carroll MD, Curtin LR, McDowell MA, Tabak CJ, Flegal KM. Prevalence of overweight and obesity in the United States, 1999-2004. JAMA. 2006;295(13):1549-1555.

3. Tzotzas T, Krassas GE. Prevalence and trends of obesity in children and adults of South Europe. Pediatr Endocrinol Rev. 2004;1 Suppl 3: 448-454.

4. Wilson PW, D'Agostino RB, Sullivan L, Parise H, Kannel WB. Overweight and obesity as determinants of cardiovascular risk: the Framingham experience. Arch Intern Med. 2002;162(16):1867-1872.

5. Yusuf S, Hawken S, Ounpuu S, et al. Effect of potentially modifiable risk factors associated with myocardial infarction in 52 countries (the INTERHEART study): case-control study. Lancet. 2004;364 (9438):937-952.

6. Calle EE, Thun MJ, Petrelli JM, Rodriguez C, Heath CW Jr. Body-mass index and mortality in a prospective cohort of US adults. NEngl J Med. 1999;341(15):1097-1105.

7. Fontaine KR, Redden DT, Wang C, Westfall AO, Allison DB. Years of life lost due to obesity. JAMA. 2003;289(2):187-193.

8. Peeters A, Barendregt JJ, Willekens F, Mackenbach JP, Al Mamun A, Bonneux L. Obesity in adulthood and its consequences for life expectancy: a life-table analysis. Ann Intern Med. 2003(1);138:24-32.

9. Snow V, Barry P, Fitterman N, Qaseem A, Weiss K. Pharmacologic and surgical management of obesity in primary care: a clinical practice guideline from the American College of Physicians. Ann Intern Med. 2005;142(7):525-531.

10. Bray GA, Greenway FL. Pharmacological treatment of the overweight patient. Pharmacol Rev. 2007;59(2):151-184.

11. Jones D. End of the line for cannabinoid receptor 1 as an anti-obesity target? Nat Rev Drug Discov. 2008;7(12):961-962. 
12. Filippatos TD, Kiortsis DN, Liberopoulos EN, Mikhailidis DP, Elisaf MS. A review of the metabolic effects of sibutramine. Curr Med Res Opin. 2005;21(3):457-468.

13. Sharma B, Henderson DC. Sibutramine: current status as an antiobesity drug and its future perspectives. Expert Opin Pharmacother. 2008;9(12):2161-2173.

14. Rolls BJ, Shide DJ, Thorwart ML, Ulbrecht JS. Sibutramine reduces food intake in non-dieting women with obesity. Obes Res. 1998;6(1):1-11.

15. Barkeling B, Elfhag K, Rooth P, Rossner S. Short-term effects of sibutramine (Reductil) on appetite and eating behaviour and the long-term therapeutic outcome. Int J Obes Relat Metab Disord. 2003;27(6):693-700.

16. Hansen DL, Toubro S, Stock MJ, Macdonald IA, Astrup A. Thermogenic effects of sibutramine in humans. Am J Clin Nutr. 1998;68(6): 1180-1186.

17. Berkowitz RI, Wadden TA, Tershakovec AM, Cronquist JL. Behavior therapy and sibutramine for the treatment of adolescent obesity: a randomized controlled trial. JAMA. 2003;289(14):1805-1812.

18. Hansen DL, Toubro S, Stock MJ, Macdonald IA, Astrup A. The effect of sibutramine on energy expenditure and appetite during chronic treatment without dietary restriction. Int J Obes Relat Metab Disord. 1999;23(10):1016-1024.

19. Hainer V, Kunesova M, Bellisle F, Hill M, Braunerova R, Wagenknecht M. Psychobehavioral and nutritional predictors of weight loss in obese women treated with sibutramine. Int J Obes (Lond). 2005;29(2):208-216.

20. Van Mil EG, Westerterp KR, Kester AD, Delemarre-van de Waal HA, Gerver WJ, Saris WH. The effect of sibutramine on energy expenditure and body composition in obese adolescents. J Clin Endocrinol Metab. 2007;92(4):1409-1414.

21. Walsh KM, Leen E, Lean ME. The effect of sibutramine on resting energy expenditure and adrenaline-induced thermogenesis in obese females. Int J Obes Relat Metab Disord. 1999;23(10):1009-1015.

22. Seagle HM, Bessesen DH, Hill JO. Effects of sibutramine on resting metabolic rate and weight loss in overweight women. Obes Res. 1998;6(2):115-121.

23. Levin BE, Dunn-Meynell AA. Sibutramine alters the central mechanisms regulating the defended body weight in diet-induced obese rats. Am J Physiol Regul Integr Comp Physiol. 2000;279(6):R2222-R2228.

24. Baranowska B, Wolińska-Witort E, Martyńska L, et al. Sibutramine therapy in obese women - effects on plasma neuropeptide Y (NPY), insulin, leptin and beta-endorphin concentrations. Neuro Endocrinol Lett. 2005;26(6):675-679.

25. Rodrigues AM, Radominski RB, Suplicy Hde L, De Almeida SM, Niclewicz PA, Boguszewski CL. The cerebrospinal fluid/serum leptin ratio during pharmacological therapy for obesity. J Clin Endocrinol Metab. 2002;87(4):1621-1626.

26. Hanotin C, Thomas F, Jones SP, Leutenegger E, Drouin P. Efficacy and tolerability of sibutramine in obese patients: a dose-ranging study. Int J Obes Relat Metab Disord. 1998;22(1):32-38.

27. Smith IG, Goulder MA. Randomized placebo-controlled trial of longterm treatment with sibutramine in mild to moderate obesity. J Fam Pract. 2001;50(6):505-512.

28. Bray GA, Blackburn GL, Ferguson JM, et al. Sibutramine produces dose-related weight loss. Obes Res. 1999;7(2):189-198.

29. Kim SH, Lee YM, Jee SH, Nam CM. Effect of sibutramine on weight loss and blood pressure: a meta-analysis of controlled trials. Obes Res. 2003;11(9):1116-1123.

30. Klein S, Burke LE, Bray GA, et al; for the American Heart Association Council on Nutrition, Physical Activity, and Metabolism. Clinical implications of obesity with specific focus on cardiovascular disease: a statement for professionals from the American Heart Association Council on Nutrition, Physical Activity, and Metabolism: endorsed by the American College of Cardiology Foundation. Circulation. 2004;110(18):2952-2967.

31. Dujovne CA, Zavoral JH, Rowe E, Mendel CM. Effects of sibutramine on body weight and serum lipids: a double-blind, randomized, placebo-controlled study in 322 overweight and obese patients with dyslipidemia. Am Heart J. 2001;142(3):489-497.
32. Hauner H, Meier M, Wendland G, Kurscheid T, Lauterbach K; for Study Group SA; SAT Study. Weight reduction by sibutramine in obese subjects in primary care medicine: the SAT Study. Exp Clin Endocrinol Diabetes. 2004;112(4):201-207.

33. Porter JA, Raebel MA, Conner DA, et al. The Long-term Outcomes of Sibutramine Effectiveness on Weight (LOSE Weight) study: evaluating the role of drug therapy within a weight management program in a group-model health maintenance organization. Am J Manag Care. 2004;10(6):369-376.

34. Rucker D, Padwal R, Li SK, Curioni C, Lau DC. Long term pharmacotherapy for obesity and overweight: updated meta-analysis. $B M J$. 2007;335(7631):1194-1199.

35. Van Gaal LF, Wauters MA, Peiffer FW, De Leeuw IH. Sibutramine and fat distribution: is there a role for pharmacotherapy in abdominal/ visceral fat reduction? Int J Obes Relat Metab Disord. 1998;22 Suppl 1: S38-S40.

36. Kamel EG, McNeill G, Van Wijk MC. Change in intra-abdominal adipose tissue volume during weight loss in obese men and women: correlation between magnetic resonance imaging and anthropometric measurements. Int J Obes Relat Metab Disord. 2000;24(5): 607-613.

37. James WP, Astrup A, Finer N, et al. Effect of sibutramine on weight maintenance after weight loss: a randomised trial. STORM Study Group. Sibutramine Trial of Obesity Reduction and Maintenance. Lancet. 2000;356(9248):2119-2125.

38. Apfelbaum M, Vague P, Ziegler O, Hanotin C, Thomas F, Leutenegger E. Long-term maintenance of weight loss after a very-low-calorie diet: a randomized blinded trial of the efficacy and tolerability of sibutramine. Am J Med. 1999;106(2):179-184.

39. Mathus-Vliegen EM. Long-term maintenance of weight loss with sibutramine in a GP setting following a specialist guided very-lowcalorie diet: a double-blind, placebo-controlled, parallel group study. Eur J Clin Nutr. 2005;59 Suppl 1:S31-S38.

40. Turk MW, Yang K, Hravnak M, Sereika SM, Ewing LJ, Burke LE. Randomized clinical trials of weight loss maintenance: a review. JCardiovasc Nurs. 2009;24(1):58-80.

41. Wadden TA, Berkowitz RI, Sarwer DB, Prus-Wisniewski R, Steinberg C. Benefits of lifestyle modification in the pharmacologic treatment of obesity: a randomized trial. Arch Intern Med. 2001;161(2):218-227.

42. Wadden TA, Berkowitz RI, Womble LG, et al. Randomized trial of lifestyle modification and pharmacotherapy for obesity. N Engl J Med. 2005;353(20):2111-2120.

43. Phelan S, Wadden TA, Berkowitz RI, et al. Impact of weight loss on the metabolic syndrome. Int J Obes (Lond). 2007;31(9):1442-1448.

44. Wirth A, Krause J. Long-term weight loss with sibutramine: a randomized controlled trial. JAMA. 2001;286(11):1331-1339.

45. Finer N, Ryan DH, Renz CL, Hewkin AC. Prediction of response to sibutramine therapy in obese non-diabetic and diabetic patients. Diabetes Obes Metab. 2006;8(2):206-213.

46. Padwal RS, Majumdar SR. Drug treatments for obesity: orlistat, sibutramine, and rimonabant. Lancet. 2007;369(9555):71-77.

47. Dahlin A, Beermann B. Incorrect use of orlistat and sibutramine in clinical practice. Eur J Clin Pharmacol. 2007;63(2):205-209.

48. Hansen D, Astrup A, Toubro S, et al; Goulder For The STORM Study Group M. Predictors of weight loss and maintenance during 2 years of treatment by sibutramine in obesity. Results from the European multi-centre STORM trial. Sibutramine Trial of Obesity Reduction and Maintenance. Int J Obes Relat Metab Disord. 2001;25(4):496-501.

49. Elfhag K, Rossner S, Barkeling B, Rooth P. Sibutramine treatment in obesity: initial eating behaviour in relation to weight loss results and changes in mood. Pharmacol Res. 2005;51(2):159-163.

50. Elfhag K, Finer N, Rossner S. Who will lose weight on sibutramine and orlistat? Psychological correlates for treatment success. Diabetes Obes Metab. 2008;10(6):498-505.

51. Peters WR, MacMurry JP, Walker J, Giese RJ Jr, Comings DE. Phenylethanolamine N-methyltransferase G-148A genetic variant and weight loss in obese women. Obes Res. 2003;11(3):415-419. 
52. Hauner H, Meier M, Jockel KH, Frey UH, Siffert W. Prediction of successful weight reduction under sibutramine therapy through genotyping of the G-protein beta3 subunit gene (GNB3) C825T polymorphism. Pharmacogenetics. 2003;13(8):453-459.

53. Grudell AB, Sweetser S, Camilleri M, et al. A controlled pharmacogenetic trial of sibutramine on weight loss and body composition in obese or overweight adults. Gastroenterology. 2008;135(4):1142-1154.

54. Weinstein AR, Sesso HD, Lee IM, et al. Relationship of physical activity vs body mass index with type 2 diabetes in women. JAMA. 2004;292(10): 1188-1194.

55. Knowler WC, Barrett-Connor E, Fowler SE, et al. Reduction in the incidence of type 2 diabetes with lifestyle intervention or metformin. N Engl J Med. 2002;346(6):393-403.

56. Tuomilehto J, Lindstrom J, Eriksson JG, et al. Prevention of type 2 diabetes mellitus by changes in lifestyle among subjects with impaired glucose tolerance. $N$ Engl J Med. 2001;344(18):1343-1350.

57. Gregg EW, Gerzoff RB, Thompson TJ, Williamson DF. Trying to lose weight, losing weight, and 9-year mortality in overweight US adults with diabetes. Diabetes Care. 2004;27(3):657-662.

58. Williamson DF, Thompson TJ, Thun M, Flanders D, Pamuk E, Byers T. Intentional weight loss and mortality among overweight individuals with diabetes. Diabetes Care. 2000;23(10):1499-1504.

59. Finer N, Bloom SR, Frost GS, Banks LM, Griffiths J. Sibutramine is effective for weight loss and diabetic control in obesity with type 2 diabetes: a randomised, double-blind, placebo-controlled study. Diabetes Obes Metab. 2000;2(2):105-112.

60. Serrano-Rios M, Melchionda N, Moreno-Carretero E. Role of sibutramine in the treatment of obese Type 2 diabetic patients receiving sulphonylurea therapy. Diabet Med. 2002;19(2):119-124.

61. Fujioka K, Seaton TB, Rowe E, et al. Weight loss with sibutramine improves glycaemic control and other metabolic parameters in obese patients with type 2 diabetes mellitus. Diabetes Obes Metab. 2000;2(3): 175-187.

62. McNulty SJ, Ur E, Williams G. A randomized trial of sibutramine in the management of obese type 2 diabetic patients treated with metformin. Diabetes Care. 2003;26(1):125-131.

63. Redmon JB, Reck KP, Raatz SK, et al. Two-year outcome of a combination of weight loss therapies for type 2 diabetes. Diabetes Care. 2005;28(6):1311-1315.

64. Arterburn DE, Crane PK, Veenstra DL. The efficacy and safety of sibutramine for weight loss: a systematic review. Arch Intern Med. 2004; 164(9):994-1003.

65. Norris SL, Zhang X, Avenell A, et al. Efficacy of pharmacotherapy for weight loss in adults with type 2 diabetes mellitus: a meta-analysis. Arch Intern Med. 2004;164(13):1395-1404.

66. Mannucci E, Dicembrini I, Rotella F, Rotella CM. Orlistat and sibutramine beyond weight loss. Nutr Metab Cardiovasc Dis. 2008;18(5):342-348.

67. Vettor R, Serra R, Fabris R, Pagano C, Federspil G. Effect of sibutramine on weight management and metabolic control in type 2 diabetes: a metaanalysis of clinical studies. Diabetes Care. 2005;28(4):942-949.

68. Daskalopoulou SS, Athyros VG, Elisaf M, Mikhailidis DP. Uric acid levels and vascular disease. Curr Med Res Opin. 2004;20(6):951-954.

69. Pi-Sunyer FX. A review of long-term studies evaluating the efficacy of weight loss in ameliorating disorders associated with obesity. Clin Ther. 1996;18(6):1006-1035.

70. Kim DM, Yoon SJ, Ahn CW, et al. Sibutramine improves fat distribution and insulin resistance, and increases serum adiponectin levels in Korean obese nondiabetic premenopausal women. Diabetes Res Clin Pract. 2004;66 Suppl 1:S139-S144.

71. McLaughlin T, Abbasi F, Lamendola C, Kim HS, Reaven GM. Metabolic changes following sibutramine-assisted weight loss in obese individuals: role of plasma free fatty acids in the insulin resistance of obesity. Metabolism. 2001;50(7):819-824.

72. Tambascia MA, Geloneze B, Repetto EM, Geloneze SR, Picolo M, Magro DO. Sibutramine enhances insulin sensitivity ameliorating metabolic parameters in a double-blind, randomized, placebo-controlled trial. Diabetes Obes Metab. 2003;5(5):338-344.
73. Parekh S, Anania FA. Abnormal lipid and glucose metabolism in obesity: implications for nonalcoholic fatty liver disease. Gastroenterology. 2007;132(6):2191-2207.

74. Sabuncu T, Nazligul Y, Karaoglanoglu M, Ucar E, Kilic FB. The effects of sibutramine and orlistat on the ultrasonographic findings, insulin resistance and liver enzyme levels in obese patients with non-alcoholic steatohepatitis. Rom J Gastroenterol. 2003;12(3):189-192.

75. Ross R. Atherosclerosis - an inflammatory disease. $N$ Engl $J$ Med. 1999;340(2):115-126.

76. Visser M, Bouter LM, McQuillan GM, Wener MH, Harris TB. Elevated C-reactive protein levels in overweight and obese adults. JAMA. 1999;282(22):2131-2135.

77. Bastard JP, Jardel C, Bruckert E, et al. Elevated levels of interleukin 6 are reduced in serum and subcutaneous adipose tissue of obese women after weight loss. J Clin Endocrinol Metab. 2000;85(9):3338-3342.

78. Festa A, D'Agostino R Jr, Howard G, Mykkanen L, Tracy RP, Haffner SM. Chronic subclinical inflammation as part of the insulin resistance syndrome: the Insulin Resistance Atherosclerosis Study (IRAS). Circulation. 2000;102(1):42-47.

79. Hak AE, Stehouwer CD, Bots ML, et al. Associations of C-reactive protein with measures of obesity, insulin resistance, and subclinical atherosclerosis in healthy, middle-aged women. Arterioscler Thromb Vasc Biol. 1999;19(8):1986-1991.

80. Shechter M, Beigel R, Freimark D, Matetzky S, Feinberg MS. Shortterm sibutramine therapy is associated with weight loss and improved endothelial function in obese patients with coronary artery disease. Am J Cardiol. 2006;97(11):1650-1653.

81. Valsamakis G, McTernan PG, Chetty R, et al. Modest weight loss and reduction in waist circumference after medical treatment are associated with favorable changes in serum adipocytokines. Metabolism. 2004;53(4):430-434.

82. Hung YJ, Chen YC, Pei D, et al. Sibutramine improves insulin sensitivity without alteration of serum adiponectin in obese subjects with Type 2 diabetes. Diabet Med. 2005;22(8):1024-1030.

83. Jung SH, Park HS, Kim KS, et al. Effect of weight loss on some serum cytokines in human obesity: increase in IL-10 after weight loss. $J$ Nutr Biochem. 2008;19(6):371-375.

84. Ahima RS, Osei SY. Adipokines in obesity. Front Horm Res. 2008;36: 182-197.

85. Quilliot D, Bohme P, Zannad F, Ziegler O. Sympathetic-leptin relationship in obesity: effect of weight loss. Metabolism. 2008;57(4):555-562.

86. Abbasi F, Lamendola C, McLaughlin T, Hayden J, Reaven GM, Reaven PD. Plasma adiponectin concentrations do not increase in association with moderate weight loss in insulin-resistant, obese women. Metabolism. 2004;53(3):280-283.

87. Faria AN, Ribeiro Filho FF, Kohlmann NE, Gouvea Ferreira SR, Zanella MT. Effects of sibutramine on abdominal fat mass, insulin resistance and blood pressure in obese hypertensive patients. Diabetes Obes Metab. 2005;7(3):246-253.

88. Arcaro G, Zamboni M, Rossi L, et al. Body fat distribution predicts the degree of endothelial dysfunction in uncomplicated obesity. Int $J$ Obes Relat Metab Disord. 1999;23(9):936-942.

89. Hashimoto M, Akishita M, Eto M, et al. The impairment of flowmediated vasodilatation in obese men with visceral fat accumulation. Int J Obes Relat Metab Disord. 1998;22(5):477-484.

90. Vakili BA, Okin PM, Devereux RB. Prognostic implications of left ventricular hypertrophy. Am Heart J. 2001;141(3):334-341.

91. Levy D, Garrison RJ, Savage DD, Kannel WB, Castelli WP. Prognostic implications of echocardiographically determined left ventricular mass in the Framingham Heart Study. N Engl J Med. 1990;322(22): 1561-1566.

92. Verdecchia P, Angeli F, Borgioni C, et al. Changes in cardiovascular risk by reduction of left ventricular mass in hypertension: a meta-analysis. Am J Hypertens. 2003;16(11Pt 1):895-899.

93. de Simone G, Devereux RB, Roman MJ, Alderman MH, Laragh JH. Relation of obesity and gender to left ventricular hypertrophy in normotensive and hypertensive adults. Hypertension. 1994;23(5):600-606. 
94. Gottdiener JS, Reda DJ, Materson BJ, et al. Importance of obesity, race and age to the cardiac structural and functional effects of hypertension. The Department of Veterans Affairs Cooperative Study Group on Antihypertensive Agents. J Am Coll Cardiol. 1994;24(6):1492-1498.

95. Wirth A, Scholze J, Sharma AM, Matiba B, Boenner G. Reduced left ventricular mass after treatment of obese patients with sibutramine: An echocardiographic multicentre study. Diabetes Obes Metab. 2006;8(6): 674-681.

96. Zannad F, Gille B, Grentzinger A, et al. Effects of sibutramine on ventricular dimensions and heart valves in obese patients during weight reduction. Am Heart J. 2002;144(3):508-515.

97. Malhotra A, White DP. Obstructive sleep apnoea. Lancet. 2002; 360(9328):237-245.

98. Caples SM, Gami AS, Somers VK. Obstructive sleep apnea. Ann Intern Med. 2005;142(3):187-197.

99. Yee BJ, Phillips CL, Banerjee D, Caterson I, Hedner JA, Grunstein RR. The effect of sibutramine-assisted weight loss in men with obstructive sleep apnoea. Int J Obes (Lond). 2007;31(1):161-168.

100. Martinez D, Basile BR. Sibutramine does not worsen sleep apnea syndrome: a randomized double-blind placebo-controlled study. Sleep Med. 2005;6(5):467-470.

101. Ehrmann DA. Polycystic ovary syndrome. NEngl J Med. 2005;352(12): 1223-1236.

102. Florakis D, Diamanti-Kandarakis E, Katsikis I, et al. Effect of hypocaloric diet plus sibutramine treatment on hormonal and metabolic features in overweight and obese women with polycystic ovary syndrome: a randomized, 24-week study. Int J Obes (Lond). 2008;32(4):692-699.

103. Lindholm A, Bixo M, Bjorn I, et al. Effect of sibutramine on weight reduction in women with polycystic ovary syndrome: a randomized, double-blind, placebo-controlled trial. Fertil Steril. 2008;89(5): 1221-1228.

104. Sabuncu T, Harma M, Harma M, Nazligul Y, Kilic F. Sibutramine has a positive effect on clinical and metabolic parameters in obese patients with polycystic ovary syndrome. Fertil Steril. 2003;80(5): 1199-1204.

105. Newcomer JW. Antipsychotic medications: metabolic and cardiovascular risk. J Clin Psychiatry. 2007;68(Suppl 4):8-13.

106. Henderson DC, Copeland PM, Daley TB, et al. A double-blind, placebo-controlled trial of sibutramine for olanzapine-associated weight gain. Am J Psychiatry. 2005;162(5):954-962.

107. Baptista T, Uzcategui E, Rangel N, et al. Metformin plus sibutramine for olanzapine-associated weight gain and metabolic dysfunction in schizophrenia: a 12-week double-blind, placebo-controlled pilot study Psychiatry Res. 2008;159(1-2):250-253.

108. Henderson DC, Fan X, Copeland PM, et al. A double-blind, placebocontrolled trial of sibutramine for clozapine-associated weight gain. Acta Psychiatr Scand. 2007;115(2):101-105.

109. Striegel-Moore RH, Franko DL. Should binge eating disorder be included in the DSM-V? A critical review of the state of the evidence. Annu Rev Clin Psychol. 2008;4:305-324.

110. Appolinario JC, Godoy-Matos A, Fontenelle LF, et al. An open-label trial of sibutramine in obese patients with binge eating disorder. J Clin Psychiatry. 2002;63(1):28-30.

111. Appolinario JC, Bacaltchuk J, Sichieri R, et al. A randomized, doubleblind, placebo-controlled study of sibutramine in the treatment of binge eating disorder. Arch Gen Psychiatry. 2003;60(11):1109-1116.

112. Milano W, Petrella C, Casella A, Capasso A, Carrino S, Milano L. Use of sibutramine, an inhibitor of the reuptake of serotonin and noradrenaline, in the treatment of binge eating disorder: a placebocontrolled study. Adv Ther. 2005;22(1):25-31.

113. Wilfley DE, Crow SJ, Hudson JI, et al. Efficacy of sibutramine for the treatment of binge eating disorder: a randomized multicenter placebocontrolled double-blind study. Am J Psychiatry. 2008;165(1):51-58.

114. Mersebach H, Klose M, Svendsen OL, Astrup A, Feldt-Rasmussen U Combined dietary and pharmacological weight management in obese hypopituitary patients. Obes Res. 2004;12(11):1835-1843.
115. Mersebach H, Svendsen OL, Astrup A, Feldt-Rasmussen U. Abnormal sympathoadrenal activity, but normal energy expenditure in hypopituitarism. J Clin Endocrinol Metab. 2003;88(12):5689-5695.

116. Wang Y, Lobstein T. Worldwide trends in childhood overweight and obesity. Int J Pediatr Obes. 2006;1(1):11-25.

117. Ogden CL, Carroll MD, Flegal KM. High body mass index for age among US children and adolescents, 2003-2006. JAMA. 2008;299(20): 2401-2405.

118. Tzotzas T, Kapantais E, Tziomalos K, et al. Epidemiological survey for the prevalence of overweight and abdominal obesity in Greek adolescents. Obesity (Silver Spring). 2008;16(7):1718-1722.

119. Wang Y, Monteiro C, Popkin BM. Trends of obesity and underweight in older children and adolescents in the United States, Brazil, China, and Russia. Am J Clin Nutr. 2002;75(6):971-977.

120. Freedman DS, Dietz WH, Srinivasan SR, Berenson GS. The relation of overweight to cardiovascular risk factors among children and adolescents: the Bogalusa Heart Study. Pediatrics. 1999;103(6 Pt 1): 1175-1182.

121. Duncan GE. Prevalence of diabetes and impaired fasting glucose levels among US adolescents: National Health and Nutrition Examination Survey, 1999-2002. Arch Pediatr Adolesc Med. 2006;160(5): 523-528.

122. Daniels SR, Arnett DK, Eckel RH, et al. Overweight in children and adolescents: pathophysiology, consequences, prevention, and treatment. Circulation. 2005;111(15):1999-2012.

123. Krassas GE, Tzotzas D. Do obese children become obese adults: childhood predictors of adult disease. Pediatr Endocrinol Rev. 2004;1(Suppl 3):455-459.

124. Gunnell DJ, Frankel SJ, Nanchahal K, Peters TJ, Davey Smith G. Childhood obesity and adult cardiovascular mortality: a 57-y followup study based on the Boyd Orr cohort. Am J Clin Nutr. 1998;67(6): 1111-1118

125. Engeland A, Bjorge T, Sogaard AJ, Tverdal A. Body mass index in adolescence in relation to total mortality: 32-year follow-up of 227,000 Norwegian boys and girls. Am J Epidemiol. 2003;157(6):517-523.

126. Berkowitz RI, Fujioka K, Daniels SR, et al. Effects of sibutramine treatment in obese adolescents: a randomized trial. Ann Intern Med. 2006;145(2):81-90.

127. Godoy-Matos A, Carraro L, Vieira A, et al. Treatment of obese adolescents with sibutramine: a randomized, double-blind, controlled study. J Clin Endocrinol Metab. 2005;90(3):1460-1465.

128. McGovern L, Johnson JN, Paulo R, et al. Treatment of pediatric obesity. A systematic review and meta-analysis of randomized trials J Clin Endocrinol Metab. 2008;93(12):4600-4605

129. Pinkney J, Wilding J, Williams G, MacFarlane I. Hypothalamic obesity in humans: what do we know and what can be done? Obes Rev. 2002;3(1):27-34.

130. Tzotzas T, Papazisis K, Perros P, Krassas GE. Use of somatostatin analogues in obesity. Drugs. 2008;68(14):1963-1973.

131. Danielsson P, Janson A, Norgren S, Marcus C. Impact sibutramine therapy in children with hypothalamic obesity or obesity with aggravating syndromes. J Clin Endocrinol Metab. 2007;92(11):4101-4106.

132. Barlow SE. Expert committee recommendations regarding the prevention, assessment, and treatment of child and adolescent overweight and obesity: summary report. Pediatrics. 2007;120 Suppl 4:S164-S192.

133. Kaya A, Aydin N, Topsever P, et al. Efficacy of sibutramine, orlistat and combination therapy on short-term weight management in obese patients. Biomed Pharmacother. 2004;58(10):582-587.

134. Sari R, Balci MK, Cakir M, Altunbas H, Karayalcin U. Comparison of efficacy of sibutramine or orlistat versus their combination in obese women. Endocr Res. 2004;30(2):159-167.

135. Gokcel A, Gumurdulu Y, Karakose H, et al. Evaluation of the safety and efficacy of sibutramine, orlistat and metformin in the treatment of obesity. Diabetes Obes Metab. 2002;4(1):49-55.

136. Erondu N, Addy C, Lu K, et al. NPY5R antagonism does not augment the weight loss efficacy of orlistat or sibutramine. Obesity (Silver Spring). 2007;15(8):2027-2042. 
137. Kiortsis DN, Tsouli S, Filippatos TD, Konitsiotis S, Elisaf MS. Effects of sibutramine and orlistat on mood in obese and overweight subjects: a randomised study. Nutr Metab Cardiovasc Dis. 2008;18(3): 207-210.

138. Derosa G, Cicero AF, Murdolo G, et al. Efficacy and safety comparative evaluation of orlistat and sibutramine treatment in hypertensive obese patients. Diabetes Obes Metab. 2005;7(1):47-55.

139. Neovius M, Johansson K, Rossner S. Head-to-head studies evaluating efficacy of pharmaco-therapy for obesity: a systematic review and meta-analysis. Obes Rev. 2008;9(5):420-427.

140. Derosa G, Cicero AF, Murdolo G, Ciccarelli L, Fogari R. Comparison of metabolic effects of orlistat and sibutramine treatment in Type 2 diabetic obese patients. Diabetes Nutr Metab. 2004;17(4): 222-229.

141. Wadden TA, Berkowitz RI, Womble LG, Sarwer DB, Arnold ME, Steinberg CM. Effects of sibutramine plus orlistat in obese women following 1 year of treatment by sibutramine alone: a placebo-controlled trial. Obes Res. 2000;8(6):431-437.

142. Hu G, Barengo NC, Tuomilehto J, Lakka TA, Nissinen A, Jousilahti P. Relationship of physical activity and body mass index to the risk of hypertension: a prospective study in Finland. Hypertension. 2004; 43(1):25-30.

143. Huang Z, Willett WC, Manson JE, et al. Body weight, weight change, and risk for hypertension in women. Ann Intern Med. 1998;128(2):81-88.

144. [No authors listed]. Effects of weight loss and sodium reduction intervention on blood pressure and hypertension incidence in overweight people with high-normal blood pressure. The Trials of Hypertension Prevention, phase II. The Trials of Hypertension Prevention Collaborative Research Group. Arch Intern Med. 1997;157(6): 657-667.

145. Stevens VJ, Obarzanek E, Cook NR, et al; for the Hypertension Prevention Research Group. Long-term weight loss and changes in blood pressure: results of the Trials of Hypertension Prevention, phase II. Ann Intern Med. 2001;134(1):1-11.

146. Jordan J, Scholze J, Matiba B, Wirth A, Hauner H, Sharma AM. Influence of Sibutramine on blood pressure: evidence from placebocontrolled trials. Int J Obes (Lond). 2005;29(5):509-516.

147. Heusser K, Engeli S, Tank J, et al. Sympathetic vasomotor tone determines blood pressure response to long-term sibutramine treatment. J Clin Endocrinol Metab. 2007;92(4):1560-1563.

148. Heusser K, Tank J, Diedrich A, et al. Influence of sibutramine treatment on sympathetic vasomotor tone in obese subjects. Clin Pharmacol Ther. 2006;79(5):500-508.

149. Birkenfeld AL, Schroeder C, Boschmann M, et al. Paradoxical effect of sibutramine on autonomic cardiovascular regulation. Circulation. 2002;106:2459-2465.
150. McMahon FG, Fujioka K, Singh BN, et al. Efficacy and safety of sibutramine in obese white and African American patients with hypertension: a 1-year, double-blind, placebo-controlled, multicenter trial. Arch Intern Med. 2000;160(14):2185-2191.

151. McMahon FG, Weinstein SP, Rowe E, Ernst KR, Johnson F, Fujioka K. Sibutramine is safe and effective for weight loss in obese patients whose hypertension is well controlled with angiotensin-converting enzyme inhibitors. J Hum Hypertens. 2002;16(1):5-11.

152. Sramek JJ, Leibowitz MT, Weinstein SP, et al. Efficacy and safety of sibutramine for weight loss in obese patients with hypertension well controlled by beta-adrenergic blocking agents: a placebo-controlled, double-blind, randomised trial. J Hum Hypertens. 2002;16(1):13-19.

153. Scholze J, Grimm E, Herrmann D, Unger T, Kintscher U. Optimal treatment of obesity-related hypertension: the Hypertension-ObesitySibutramine (HOS) study. Circulation. 2007;115(15):1991-1998.

154. Horvath K, Jeitler K, Siering U, et al. Long-term effects of weightreducing interventions in hypertensive patients: systematic review and meta-analysis. Arch Intern Med. 2008;168(6):571-580.

155. Cook S, Togni M, Schaub MC, Wenaweser P, Hess OM. High heart rate: a cardiovascular risk factor? Eur Heart J. 2006;27(20):2387-2393.

156. Gillum RF, Makuc DM, Feldman JJ. Pulse rate, coronary heart disease, and death: the NHANES I Epidemiologic Follow-up Study. Am Heart J. 1991;121(1 Pt 1):172-177.

157. Ernest D, Gershenzon A, Corallo CE, Nagappan R. Sibutramineassociated QT interval prolongation and cardiac arrest. Ann Pharmacother. 2008;42(10):1514-1517.

158. Harrison-Woolrych M, Clark DW, Hill GR, Rees MI, Skinner JR. QT interval prolongation associated with sibutramine treatment. Br J Clin Pharmacol. 2006;61(4):464-469.

159. Padwal R, Kezouh A, Levine M, Etminan M. Long-term persistence with orlistat and sibutramine in a population-based cohort. Int J Obes (Lond). 2007;31(10):1567-1570.

160. Perrio MJ, Wilton LV, Shakir SA. The safety profiles of orlistat and sibutramine: results of prescription-event monitoring studies in England. Obesity (Silver Spring). 2007;15(11):2712-2722.

161. Hill GR, Ashton J, Harrison-Woolrych M. Sibutramine usage in New Zealand: an analysis of prescription data by the Intensive Medicines Monitoring Programme. Pharmacoepidemiol. Drug Saf. 2007;16(11): 1217-1226.

162. James WP. The SCOUT study: risk-benefit profile of sibutramine in overweight high-risk cardiovascular patients. Eur Heart J Supplements. 2005; 7(suppl L):L44-L48.

163. Torp-Pedersen C, Caterson I, Coutinho W, et al; SCOUT Investigators. Cardiovascular responses to weight management and sibutramine in high-risk subjects: an analysis from the SCOUT trial. Eur Heart $J$. 2007;28(23):2915-2923.
Vascular Health and Risk Management

\section{Publish your work in this journal}

Vascular Health and Risk Management is an international, peerreviewed journal of therapeutics and risk management, focusing on concise rapid reporting of clinical studies on the processes involved in the maintenance of vascular health; the monitoring, prevention and treatment of vascular disease and its sequelae; and the involvement of

\section{Dovepress}

metabolic disorders, particularly diabetes. This journal is indexed on PubMed Central and MedLine. The manuscript management system is completely online and includes a very quick and fair peer-review system, which is all easy to use. Visit http://www.dovepress.com/ testimonials.php to read real quotes from published authors. 